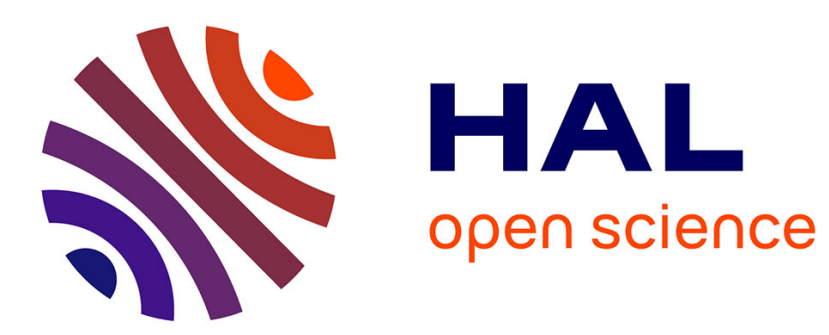

\title{
MATERIAL CONSIDERATION FOR VERTICAL BLOCH LINE MEMORY
}

\author{
G. Ronan, W. Clegg, S. Konishi
}

\section{To cite this version:}

G. Ronan, W. Clegg, S. Konishi. MATERIAL CONSIDERATION FOR VERTICAL BLOCH LINE MEMORY. Journal de Physique Colloques, 1985, 46 (C6), pp.C6-127-C6-130. 10.1051/jphyscol:1985622 . jpa-00224869

\section{HAL Id: jpa-00224869 https://hal.science/jpa-00224869}

Submitted on 1 Jan 1985

HAL is a multi-disciplinary open access archive for the deposit and dissemination of scientific research documents, whether they are published or not. The documents may come from teaching and research institutions in France or abroad, or from public or private research centers.
L'archive ouverte pluridisciplinaire HAL, est destinée au dépôt et à la diffusion de documents scientifiques de niveau recherche, publiés ou non, émanant des établissements d'enseignement et de recherche français ou étrangers, des laboratoires publics ou privés. 


\author{
G. Ronan, W. Clegg and S. Konishi ${ }^{+}$ \\ Department of Electrical Engineering, University of Manchester, \\ Manchester M13 SPL, U.K. \\ ${ }^{+}$Department of Electrical Engineering, Kyushyu University, Fukuoka, Japan
}

\begin{abstract}
Résumé - Un modèle simplifié de la paroi séparant deux domaines est employé afin d'envisager les exigences d'un matériau qui conduiraient à l'élaboration d'un film de grenat à bulles typiquement adapté aux besoins spécifiques de la mémoire VBL. Un matériau à large $Q$, faible épaisseur (h $\simeq 3-4 \iota$ ) et grand $\alpha$ paraitrait pouvoir optimiser la force gyrotropique du champ agissant et minimiser 1 'attraction VBL paire-paire non-désirée. Cependant, pour minimiser l'amplitude du puits de potentiel et celle du champ agissant, il apparaitrait avantageux d'accroitre la séparation entre bits jusqu'à uné valeur de l'ordre de $0,8 \mathrm{sw}$.
\end{abstract}

Abstract - A simplified model of a domain wall is employed to considex some of the material requirements that would tailor a typical bubble garnet film to the specific needs of VBI memory. A large $Q$, low thickness $(h \simeq 3-4 l$ ), high a material would appear to optimise drive field gyrotropic force and minimise the undesirable VBL pair-pair attraction. Even so, to minimise the required potential well and drive field amplitudes, it would appear expedient to increase the bit separation to be of the order of $0.8 \mathrm{sw}$.

\title{
Introduction
}

In the proposed VBL memory (1) the presence or absence of a pair of negative VBL injected in a stripe domain wall act as a binary $' 1$ ' or $' 0{ }^{\prime}$. A periodic in-plane field potential well structure defines the bit position and a perpendicular drive fjeld provides a gyrotropic force sufficient to propagate a VBL pair out of one potential well into the next. For this discussion we assume a VBL is represented as a point magnetic charge and consider the in-plane field component parallel to the wall arising from convergence (or divexgence) of magnetisation in the flanking Bloch wall regions. This so called ' $\sigma$-charge' gives rise to a non local effect which interacts with similar poles at different positions on the wall. If we consider a VBL as a line with regions of wall magnetisation angle $\phi_{W}=0$ and $\pi$ on either flank then the magnetic moment of the VBL is simply $2 M$. Including the wall width, $\pi \Delta$, and the material thickness, $h$, then the total magnetic charge, $m$, is given by $2 m M \Delta h$. our model therefore assumes a point charge as opposed to the charge distribution which would require a very much more detailed study, and ignores variation of charge through the thickness. (This latter point shall be considered in conclusion.) The magnetic field parallel to the wall resultant from this point charge is $\mathrm{m} / \mathrm{r}^{2}$, and the force acting on the charge due to a magnetic field is $\mathrm{m} . \mathrm{H}$.

\section{Attractive Force Between VBL Pairs}

Let us consider the effective field resultant from a pair of negative VBL as shown in Figure 1. The field at $p$ a distance $x$ from the centre of the vBL paix is

$$
\begin{aligned}
H_{p} & =2 M \pi \Delta h\left\{\frac{1}{\left(x+\frac{\pi \Lambda}{2}\right)^{2}}-\frac{1}{\left(x-\frac{\pi \Lambda}{2}\right)^{2}}\right\} \\
& \simeq-4 \pi M \Delta \pi \Lambda \mathrm{h} / \mathrm{x}^{3}
\end{aligned}
$$$$
\text { …(1) }
$$ 


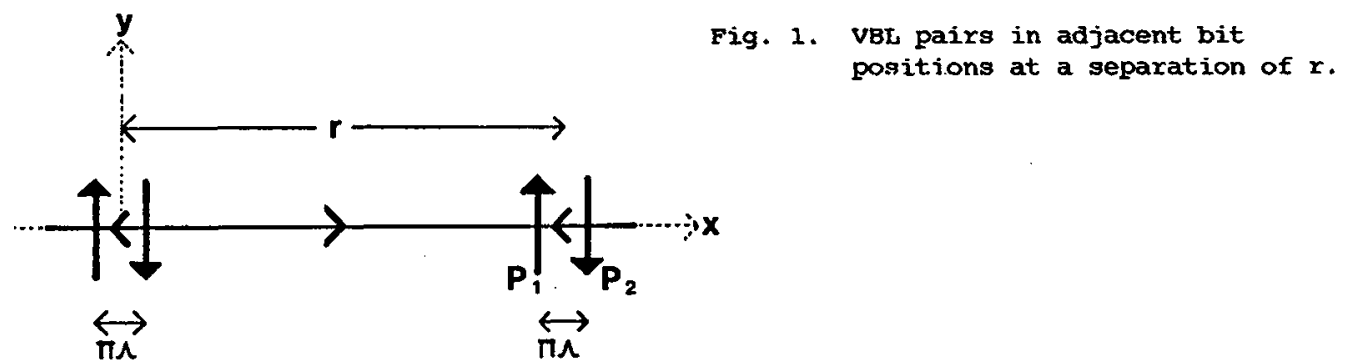

for the VBL spacing, $\pi \Lambda, \ll<x$. With reference to Figure I the attractive force on a pair of VBL a distance $r$ fxom the initial pair is given by,

$$
F_{\text {att }}=2 \pi M \Delta h \mathrm{H}\left(\mathrm{P}_{1}\right)-2 \pi M \Delta h \mathrm{H}\left(\mathrm{P}_{2}\right)
$$

where $H_{(p)}$ is the field at $p$. Therefore

$$
\left.F_{\text {att }}=2 \pi M \Delta h \cdot \pi \Lambda \cdot \frac{\delta \mathrm{H}}{\delta \mathrm{X}}\right)_{\mathrm{X}=\mathrm{r}}
$$

which from equation (2) is

$$
P_{\text {att }}=24 \pi^{4} M^{2} \Delta^{2} \Lambda^{2} h^{2} / r^{4}
$$

substituting $\Delta=\mathrm{l} / 20$

$$
\text { and } \Lambda=i / 2 \sqrt{Q}
$$

we are left with

$$
P_{\text {att }}=3 \pi^{3} \frac{\mathrm{A}}{Q^{2}} \imath^{2} h^{2} / x^{4}
$$

\section{Potential Well Restoring Force}

If we assume a sinusoidal potential well of the form

$$
\mathrm{E}_{w}=\mathrm{t}_{\mathrm{m}} \cos \frac{2 \pi}{\mathrm{r}} \times
$$

then in a similar manner to equ. 4 the restoring force on a VBL pair is

$$
\mathbf{P}_{R}=-2 \pi^{2} M \Delta M h \frac{2 \pi}{r} k_{m} \sin \frac{2 \pi}{r} x
$$

which is a maximum at $x=r / 4$ and $x=3 r / 4$. Ideally as Fatt $\alpha 2 / x^{4}$ it would be preferable to have the maximum restoring force at $x=0$ and $x=x$ reducing the required amplitude of $H_{m}$ and thus the magnitude of the drive field. A simple solution would be a triangular potential well as shall be discussed at a later date. For the present, however, we shall consider the case of maximum restoring force at $x$ $=0, x$ and with the substitutions of equ. 6 and 7 ,

$$
\begin{aligned}
& F_{\text {max }}=2 \pi^{2} \operatorname{M\Delta Nh2\pi H_{m}/r} \\
& =-\frac{\pi^{2}}{Q} \sqrt{2 \pi A} H_{m} \ln / x
\end{aligned}
$$$$
\ldots(11)
$$

\section{Drive Field Gyrotropic Force}

The gyrotropic force associated with a pexpendicular drive field is more ambiguous as it is airectly related to the density of VBL in the domain wall. The gyrotropic 
force on a VBL is (2)

$$
\mathbf{F}_{\mathbf{g}}=\frac{2 \pi \mathrm{M}}{\gamma} \mathrm{h} v_{\mathrm{Y}}
$$

$v_{y}$ is the domain wall velocity which from the mobility of a 'hard' wall (i.e., $r$ \& $2 \pi \Lambda$ ) is

$$
v_{Y}=\alpha y \Delta H_{z}
$$

where $\mathrm{H}_{\mathrm{Z}}$ is the sum of perpendicular components of effective fields, i.e., demagnetising, wall curvature and applied fields. Oux initial assumption for $f_{a t t}$ however was that $r>>\pi \Lambda$ which would suppose that the wall would move at a higher velocity although not that of a 'soft' wall given by

$$
u_{\mathbf{Y}}=\underset{\alpha}{\gamma \Delta} \mathbf{H}_{\mathbf{z}}
$$

As $\alpha<<\mid$ there would appear to be a considerable uncertainty as to the magnitude of the gyrotropic force (although this may be estimated by numerical solutions of domain wall motion ( 3 )). Combining equ, 13 and 14 one can however say that this force is in excess of

$$
\begin{aligned}
F_{\text {gmin }} & =2 \pi M \alpha \Delta \mathrm{hH}_{z} \\
& =\sqrt{\frac{2 \pi \mathrm{A}}{Q}} \text { aht }_{z}
\end{aligned}
$$

which is suffice for the present aiscussion.

\section{Material Considerations}

Comparing the three forces equations 8,12 and 17 the requixements to be met are minimise $f_{\text {att }}$ so that the potential well magnitude $\mathrm{F}_{\mathrm{m}}$ is minimised reducing the required gyrotxopic force while maintaining the bit period $r$ low. of the variables in question $l$ can be taken as $S w / 8$ and the exchange constant $A$ can be assumed constant at $\approx 2 \times 10^{-7} \mathrm{erg} / \mathrm{cm}$. Immediately obvjous is that a low $\mathrm{h}(\approx 3-4 \mathrm{l}) \mathrm{high} Q$ $(=4)$ material reduces the relative effect of $F_{\text {att }}$ and that a high $\alpha(\simeq 0.1-0.2)$ increases Fgmin. This latter one would intuitively expect as large damping decreases domain distortion and laxge VBL oscillatory effects during propagation (3). The upper limit on $\alpha$ can be seen from the ratio of VBL velocity to wall velocity (4),

$$
v_{\text {VBL }} \alpha \frac{1}{\alpha} v_{\text {wall }}
$$

i.e., a large damping increases the ratio $v_{\text {wall }} / v_{\text {VBL }}$ increasing the required wall displacement and thus $\mathrm{H}_{\mathrm{z}}$ (xemembering that $\mathrm{H}_{\mathrm{z}}$ is an effective field resultant from drive, demagnetising and wall bending effects). The criterion high $Q$ is straight forward as one would requixe large $Q$ to maintain VBL stability. A possible disadvantage of a thin material ( $=3-4 l$ ) might be in detection (magnetoresistive detection of bubble domains) although as it is only the detector that is to be of permalloy a thin film detector with high signal: noise could be employed.

In conclusion to estimate density $(x)$ we consider a material with $\alpha=0.1, Q=4, h=4 l, L=s_{w / 8}$ and $A=2 \times 10^{-7} \mathrm{erg} / \mathrm{cm}$.

\section{Density}

It would clearly be desirable to have $P_{\text {Rmax }} \gg F_{\text {att }}$ not only to ensure stability of the bit positions, but also for successful propagation of a random bit pattern. Taking therefore $F_{\operatorname{Rmax}}=10 F_{\text {att }}$ and combining equations 8 and 12 , a relationship between potential well depth $\left(\mathrm{H}_{\mathrm{m}}\right)$ and bit period:stripe width ratio $\left(\mathrm{r} / \mathrm{s}_{\mathrm{w}}\right) \mathrm{can}$ be 

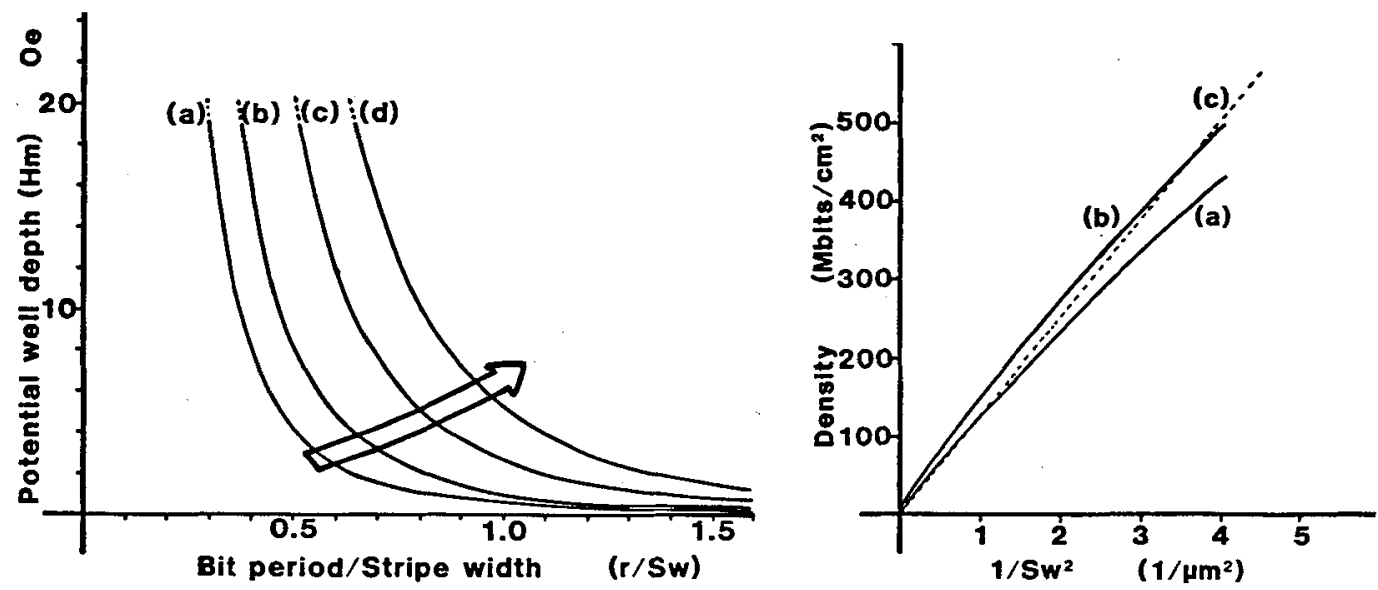

Fig. 3. Density as a function of $1 / s^{2}$ for (a) the simple

Fig. 2. Potential well depth as a function of bit period: stripe width ratio for strip width of (a) $5 \mu \mathrm{m}$, (b) $2.5 \mu \mathrm{m}$, (c) $1.0 \mu \mathrm{m}$, charge model, (b) the revised charge model (d) $0.5 \mu \mathrm{m}$. accounting for charge variation through thickness and (c) $r=0.85 w$.

obtained as shown for various stripe widths in Fig. 2. The expected potential well depth for decreasing stripe width is shown approximately as an arrow from which an estimation of the bit period can be made. (The positioning of the axrow is derived from previous numerical calculations of VBL propagation ( 3 ) and unpublished results, but it can be seen to correspond approximately to the 'knee' of the curves.) As is expected potential well depth increases sharply with decreasing bit period and the corresponding densities $\left(=1 / x \times s_{w}\right.$ bits $\left./ \mathrm{cm}^{2}\right)$ varies approximately as a function of $1 / s_{w}^{2}$. (see Fig. 3.)

A more detailed estimation of VBL magnetic charge accounting for variation of wall magnetisation angle through the material thickness, gives a smaller VBL charge and (following the same argument as above) as shown on Fig. 3 a density which approaches 500mits/ $\mathrm{cm}^{2}$ for $0.5 \mu \mathrm{m}$ stripe width. We must therefore conclude that the above model is conservative and that in practice some gain in density would be achieved. However as a rule of thumb, bit spacing of the order $0.8 S_{w}$ (four times the VBL pair width) could be used. This may be considered somewhat analogous to the required bit spacing of foux times the bubble diameter in a conventional bubble device although in that case the relevant force is repulsive.

\section{Conclusion}

Design rules have been proposed fox vBL memory using a simple point charge model. Although the model is considered conservative two important conclusions can be drawn from it. Firstly a low thickness $(h \simeq 4 L$ ) material reduces the relative effect of the mutual attraction between VBI pairs and secondly the bit period should be of the order $0.8 \mathrm{~s}_{w}$. In comparison to a conventional bubble memory cell area (16 $\mathrm{s}_{w}{ }^{2}$ ) an increase in density of twenty fold is expected. Considerations of fabrication requirements for such a device while beyond the scope of this present work are to be covered at a later date.

\section{References}

1. Konishi, S., I.E.E.E. Trans. Magn., Mag-19, p. 1838, 1983.

2. Malozemoff and Slonczewski, "Magnetic Domain Walls in Bubble Materials", Applied Solid state Science, p. 162, Academic Pxess Inc., 1979.

3. Matsuyama, K. and Konishi, S., T.E.E.E. Trans. Magn., Mag-20, p. 1141, 1984.

4. Konishi, S., Matsuyama, K., Chida, I., Kubota, S., Kawahara, H, and Ohbo, M., I.F.E.E. Trans. Magn., Mag-20, P. J129, 1984. 